\title{
Current trends in dental implants
}

\author{
Laura Gaviria, John Paul Salcido, Teja Guda, Joo L. Ong \\ Department of Biomedical Engineering, The University of Texas at San Antonio, San Antonio, TX, USA
}

\begin{abstract}
J Korean Assoc Oral Maxillofac Surg 2014;40:50-60)
Tooth loss is very a very common problem; therefore, the use of dental implants is also a common practice. Although research on dental implant designs, materials and techniques has increased in the past few years and is expected to expand in the future, there is still a lot of work involved in the use of better biomaterials, implant design, surface modification and functionalization of surfaces to improve the long-term outcomes of the treatment. This paper provides a brief history and evolution of dental implants. It also describes the types of implants that have been developed, and the parameters that are presently used in the design of dental implants. Finally, it describes the trends that are employed to improve dental implant surfaces, and current technologies used for the analysis and design of the implants.
\end{abstract}

Key words: Dental implants, History, Design, Surfaces, Osseointegration

[paper submitted 2014. 3. 20 / accepted 2014. 4. 2]

\section{Introduction}

Tooth loss is very common and it can happen as a result of disease and trauma; therefore, the use of dental implants to provide support for replacement of missing teeth has a long and multifaceted history ${ }^{1-5}$.

Statistics provided by the American Association of Oral and Maxillofacial Surgeons show that $69 \%$ of adults ages 35 to 44 have lost at least one permanent tooth to an accident, gum disease, a failed root canal or tooth decay. Furthermore, by age $74,26 \%$ of adults have lost all of their permanent teeth $^{6}$. Therefore, the use of dental implants reveals that about 100,000-300,000 dental implants are placed per year, which approximates the numbers of artificial hip and knee joints placed per year ${ }^{7}$.

Research on dental implant designs, materials and techniques has increased in the past few years and is expected to

\footnotetext{
Joo L. Ong

Department of Biomedical Engineering, The University of Texas at San Antonio, One UTSA Circle, AET 1.102, San Antonio, TX 78249, USA

TEL: +1-210-458-7084 FAX: +1-210-458-7007

E-mail:anson.ong@utsa.edu

(C) This is an open-access article distributed under the terms of the Creative Commons Attribution Non-Commercial License (http://creativecommons.org/licenses/by-nc/3.0/), which permits unrestricted non-commercial use, distribution, and reproduction in any medium, provided the original work is properly cited.

Copyright (C) 2014 The Korean Association of Oral and Maxillofacial Surgeons. All rights reserved.
}

expand in the future ${ }^{1,4,8}$ due to the recent growth of the global market for dental implants and the rising in the demand for cosmetic dentistry.

\section{Dental Implant Evolution}

The history of dental implants can be traced back to ancient Egypt, where carved seashells and/or stones were placed into human jaw bone to replace missing teeth. Other documented examples of early implants are those fabricated from noble metals and shaped to recreate natural roots ${ }^{9}$.

Dental implants have a history of several centuries starting with the early civilizations more than 2,000 years ago in South and North America and regions of the Middle Asia and Mediterranean. Archeological findings have indicated that these civilizations replaced missing teeth using carved stone, shells, bones and gold ${ }^{3,10}$.

Around 1930s, archaeological excavations in Honduras revealed that the Mayan civilization had the earliest known examples of dental implants, dating from about $600 \mathrm{AD}$, when a fragment of mandible with implants was found. The specimen had three pieces of shells carved into tooth shapes placed into the sockets of three missing lower incisor teeth. Later on, it was also observed that there was compact bone formation around two of the implants ${ }^{4,11}$.

In the Middle Ages, dental implantation was performed by 
using allografts and xenografts. However, this practice didn't become very popular, since it was identified as the reason for infectious diseases and even deaths ${ }^{4,10}$.

Modern dental implant history starts during World War II when in the years of service in the army, Dr. Norman Goldberg thought about dental restoration using metals that were used to replace other parts of the body ${ }^{12}$. Later on in 1948, in association with Dr. Aaron Gershkoff, they produced the first successful sub-periosteal implant ${ }^{12}$. This success formed the foundation of implant dentistry in which they were pioneers in teaching techniques in dental schools and dental societies around the world ${ }^{4,12}$.

One of the most important developments in dental implantology occurred in 1957, when a Swedish orthopedic surgeon by the name of Per-Ingvar Brånemark began studying bone healing and regeneration and discovered that bone could grow in proximity with the titanium (Ti), and that it could effectively be adhered to the metal without being rejected ${ }^{13}$. Therefore, Brånemark called this phenomenon 'osseointegration', and he carried out many further studies using both animal and human subjects. In 1965, he placed the first Ti dental implants into a 34-year-old human patient with missing teeth due to severe chin and jaw deformities. Brånemark inserted four Ti fixtures into the patient's mandible, and several months later he used the fixtures as the foundation for a fixed set of prosthetic teeth ${ }^{4}$. The dental implants served for more than 40 years, until the end of the patient's life - $^{2-4,10,11,13}$.

Brånemark published many studies on the use of Ti implants, and between 1978 and 1981, he cofounded a company for the development and marketing of dental implants. Brånemark's discovery had such a profound impact in dentistry that to the present day, over 7 million Brånemark System implants have now been placed and hundreds of other companies produce dental implants ${ }^{11,13}$.

In May of 1982, Brånemark presented the results of his 15 years of human and animal research at the Toronto Conference on Osseointegration in Clinical Dentistry, and shortly after the conference, researchers from the United States were trained in Brånemark's methods in Sweden ${ }^{4,14}$.

In 1982, the US Food and Drug Administration approved the use of Ti dental implants, and in 1983, Dr. Matts Andersson developed the Procera (Nobel Biocare, Zurich, Switzerland) computer-aided design and computer-aided manufacturing (CAD/CAM) method of high precision, repeatable manufacturing of dental crowns ${ }^{15}$. Recent progress in the past century has focused on materials and techniques to improve quality and anchorage ${ }^{16}$; and after the mid-1980s, other im- portant developments in dental implantology have been focused in the esthetic restorations ${ }^{4}$.

The development of modern ceramics started in 1992; and from that time on, dental implant companies, have incorporated ceramic surface treatments and ceramic-like elements to implants with the purpose of further enhancing osseointegration $^{3,15}$.

Today, approximately 450,000 osseointegrated dental implants are being placed every year, with an expectation of $95 \%$ success rate (in the case of single tooth replacement with an implant supported crown), with minimum risks and associated complications ${ }^{4}$.

\section{Types of Dental Implants}

There are have been four main types of dental implant designs that have been developed and used in clinical dentistry, including a subperiosteal form, blade form, ramus frame, and endosseous form ${ }^{17}$. However, the large scope of this review will focus on endosseous implants which are the most used in dentistry today.

Endosseous dental implants are typically screw-shaped, inserted into either the maxilla or mandible, and serve to replace the tooth root. Typically, dental implants are made out of grade 4 commercially pure Ti because it is corrosion resistant and stronger than other grades. However, Ti alloys, mainly Ti6Al4V, are also used since it is stronger and more fatigue resistant that pure $\mathrm{Ti}^{18}$. In bulk form, endosseous implants largely differ by the overall shape of the implant (e.g., tapered versus cylindrical) and macro-topography. Several parameters in the design of endosseous implants affect survival rates of implants, including: body shape, size, chemical surface composition, and topographical features among other factors.

\section{Macro features of endosseous implants}

Dental implants are designed to achieve primary mechanical stability and to promote a strong bone-implant interaction over time through osseointegration ${ }^{19,20}$. For endosseous implants, there are three major macro-aspects: 1) screw threads, 2) solid body press-fit designs (cylindrical, conical), and/or 3 ) porous-coated designs ${ }^{21,22}$. Each configuration affects the long-term biomechanical properties at the bone-implant interface and they largely determine success or failure of the implant. Bone adapts to stress concentrations from the implant interface by inducing either hypertrophy or atrophy ${ }^{23,24}$. Thus, 
an optimal shape will allow for equal distribution of stress to the surrounding bone matrix and to promote bone growth.

Screw thread type implants are the most popular type of root implant due to their proven success ${ }^{25}$ and great initial retention strengths ${ }^{9}$. Several parameters in the thread design affect the success of the implant, including thread pitch, thread height, and thread configuration (v-shaped, square-shaped, etc) ${ }^{9}$. It should be noted that cortical bone is not significantly affected by the shape of the implant ${ }^{26}$. However, the behavior of trabecular bone is greatly influenced by the shape of the threads ${ }^{26}$.

Thread pitch is the distance from the center of one thread to the center of the next thread. Pitch predominantly plays a role in determining available surface area for bone interaction and is thus an important design parameter ${ }^{9}$. For a fixed length screw, the lower the pitch, the more threads there are available. Chun et al. ${ }^{27}$ showed that by decreasing pitch length, maximum effective stresses decrease, thus indicating that less stress exposed to bone is required to hold the implant stable. From the same study, it was shown that increasing the length of the implant decreased the maximum effective stress. In a similar 2-dimensional finite element analysis (FEA) by Motoyoshi et al. ${ }^{28}$, a decrease in pitch resulted in a decrease of maximum effective strength. However, the influence of stress distributions as a result of pitch were unclear.

As reviewed by Geng et al. ${ }^{29}$ in 2004 , there are four common thread configurations: v-thread, thin-thread, reverse buttress, and square thread. Using FEA, Geng et al. ${ }^{29}$ showed that truncated $\mathrm{v}$-thread $(0.1 \mathrm{~mm}$ width thread apex $)$ and a large square thread $(0.36 \mathrm{~mm}$ thread width) designs are beneficial in dissipating stresses evenly and that thin thread type forms $(0.1 \mathrm{~mm}$ width $)$ should be avoided due to large stress concentrations in bone. However, other FEA studies suggest that thread profiles do not affect von Mises stress distributions in bone ${ }^{30}$. In an animal study, square thread implants outperformed v-thread and buttress designs in bone-toimplant contact and torque removal after 12 weeks ${ }^{31}$.

Among the various parameters, screws can be self-tapping, thus negating the need to drill pilot holes. However, it was reported that the initial stability of non-self-tapping implants was greater compared to self-tapping implants of the same material using polyurethane blocks to simulate bone with resonance frequency analysis ${ }^{32}$. This is thought to be attributed to greater surface area available on non-self-tapping screws due the availability of more threads ${ }^{32}$.

There is great debate in the optimal overall shape of the implant (i.e., threaded versus smooth). As previously stated, initial mechanical stability largely determines the success of an implant. As such, mechanical considerations must first be taken into account to minimize micromovement of the implant once loaded ${ }^{20}$. In comparing threaded cylindrical implants versus threaded conical implants, Kim et al. ${ }^{33}$ found that the primary stability of conical implants is greater than cylindrical implants. However, the results of this canine study showed that cylindrical implants had higher success rates, though they it was not significantly different ${ }^{33}$. Conical implants were thought to cause over compression on the surrounding bone matrix, thus causing biological damage ${ }^{33}$. In an animal study, comparing threaded Ti implants, threaded hydroxyapatite coated Ti implants, and smooth Ti implants, threaded implants outperformed smooth implants with survival rates of $95.5 \%$ to $75.4 \%$, respectively ${ }^{25}$.

\section{Implant-abutment connection}

The implant-abutment connection can be thought of as the head of the implant; the function of the connection is to provide a means to apply torque to screw the body of the implant into bone and to provide a second-stage connection for the abutment ${ }^{34}$. There are 2 basic forms of the connector consisting of either an internal or external connector which is typically hex shaped. In both cases with respect to coupling, the head must prevent rotation of the abutment and allow for the use of interchangeable parts in the case that a component needs to be replaced ${ }^{35}$. Originally, the external hex connector was developed but was redesigned so that it could withstand higher occlusal forces and minimize micro-movement between the implant and the abutment since this interface determines joint $\operatorname{strength}^{35}$. Internal hex implants were then developed to increase stability between the implant and abutment.

\section{Implant Requirements and Desgin}

Since the use of dental implants has a long history, there are many factors that have been recognized as critical for the successful performance of the implants ${ }^{8}$. One of the most important factors is biocompatibility; which not only involves compatibility of the material with the tissue but its ability to perform a specific function. Therefore, this property is not dependent just on the physical, chemical and mechanical properties of the material, but also by the application in which the material is used. In the case of dental implants, the biocompatibility of materials is evaluated by studying the di- 


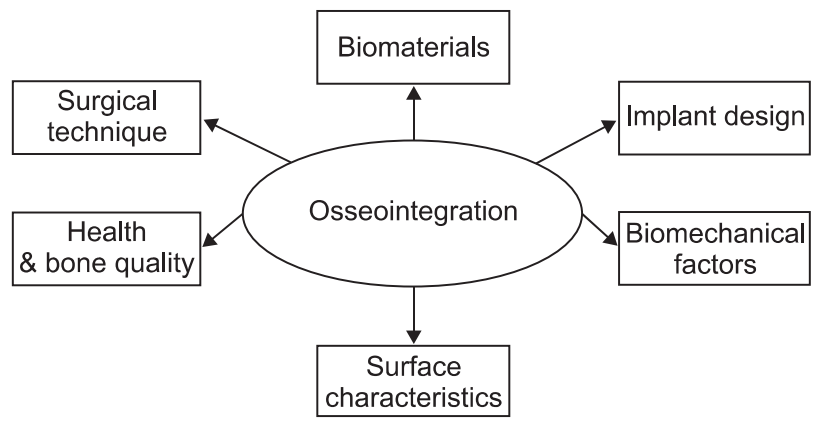

Fig. 1. Factors that affect osseointegration. Laura Gaviria et al: Current trends in dental implants. J Korean Assoc Oral Maxillofac Surg 2014

rect interactions between the implant and the tissues, which is a measurement of the degree of osseointegration ${ }^{1,2,36}$. In order to improve osseointegration; therefore long-term success of the implants, the following variables are critical and should be considered in the design of dental implants include biomaterials composition, implant width length and geometry, biomechanical factors, surface characteristics, medical status of the patient, bone quality and surgical technique ${ }^{4,8,37}$.(Fig. 1)

\section{Biomaterials}

The biomaterials used for manufacturing dental implants include metals, ceramics, carbons, polymers, and combinations of these. Polymers are softer and more flexible than the other classes of biomaterials. They also present with low mechanical strength, which makes them prone to mechanical fractures during function under high loading forces. Polymeric materials were reported to have very little application in implant dentistry and were only used to fabricate shockabsorbing components placed between the implant and the suprastructure $^{37}$.

Ti, including alloy Ti-6Al-4V (Ti-6 aluminum-4 vanadium), is the first modern material used for dental implants, and it is still one of the most used in contemporary dental implants. Commercially pure $\mathrm{Ti}$ is a light metal with excellent biocompatibility, relatively high stiffness and high resistance to corrosion ${ }^{8,37}$. However, when exposed to air, a surface oxide is formed and this layer of oxide determines the biological response $\mathrm{e}^{2}$. This oxide layer is a dynamic interface that acts as platform for the apposition of bone matrix ${ }^{37}$.

Other metals have been used for osseointegration, including zirconium, gold and Ti-aluminum-vanadium alloys. These alloys may strengthen the implant but have been shown to have relatively poor bone-to-implant contact ${ }^{2}$.
Bioceramics such as hydroxyapatite are also used because although their low strength, excellent biocompatibility, and capacity to integrate with hard tissue and living bone ${ }^{8}$. Besides their brittle nature, hydroxyapatite, tricalcium phosphate, and aluminum oxide ceramics are currently used as plasma-sprayed coatings onto a metallic core ${ }^{37}$. This results in union of the implant with the host tissue ${ }^{1}$.

\section{Implant design}

A wide variety of different sizes and shapes of implants have evolved to fit current surgical concepts and improve patient treatment. Continuous research has revealed that subtle changes in shape, length, and width of the implants could influence success rates ${ }^{2,9}$.

\section{1) Length}

Implant length and diameter have an influence on the stress distribution at the bone-implant interface, as well as on success rates ${ }^{38}$. Implant length is the dimension from the platform to the apex of implant ${ }^{9}$. Implant length varies from 6-20 millimeters. The most common length employed are between 8-15 millimeters ${ }^{2}$. Research in implant dentistry has shown that longer implants guarantee better success rates and prognosis; and that shorter implants have statistically lower success rates due to reduced stability, which can be explained in terms of less bone to implant contact and smaller implant surface $^{2,5,9}$. However, short or narrow implants are preferred for the prosthetic solution of the extremely resorbed alveolar bone areas $^{5,39}$.

\section{2) Diameter}

The diameter of the implant is measured from the widest point of a thread to the opposite point on the implant and typically ranges from 3 to $7 \mathrm{~mm}$; although narrower diameter implants can be used in small spaces ${ }^{2,5,9}$. For clinical applications, physicians select implant diameter depending on the patient's bone quantity and quality to yield optimal stability and to prohibit over-instrumentation. For example, wider implants allow for interaction with a larger amount of bone? Ivanoff et al. ${ }^{40}$ concluded from animal studies that larger diameter implants are more stable ${ }^{5,9}$ in removal torque tests, and that they may be more useful in the clinical setting since there is a larger contact area with cortical bone. In addition, it has been shown in mechanical simulations that larger diameter implants can resist larger vertical loads ${ }^{41}$. Using FEA, it was determined that the implant diameter was much more 
important in stress dissipation than implant length, especially in cortical bone ${ }^{42}$, though other groups have reported that the length of the implant was more important in controlling stress distribution in the cancellous bone ${ }^{43}$. Based off of the literature, implant lengths ranging from $8 \mathrm{~mm}$ to $12 \mathrm{~mm}$ are used clinically.

\section{3) Geometry}

One of the main concerns in terms of design is the shape of the implant, since the geometry affects the interaction between the bone and implant, the surface area, the distribution of forces to the bone and the stability of the implant ${ }^{1}$. Therefore, commercial dental implants are classified into different groups according to their shape. The main types of implants are cylindrical, conical, stepped, screw-shaped, and hollow cylindrical. Several studies revealed that conical implant surfaces or surfaces with geometric discontinuities resulted in higher stresses than smoother shapes such as cylindrical or screw-shaped ${ }^{1,8,9}$. For this reason, the cylindrical screw threaded implants are the most commonly used ${ }^{1}$.

\section{4) Threads}

As mentioned before, threads are incorporated into implants in order to improve initial stability, enlarge implant surface area, distribute stress favorably ${ }^{36}$ while minimizing the amount of extreme adverse stresses to the bone-implant interface ${ }^{39,44}$. The thread profile is characterized by the depth, pitch (number of threads per unit length) ${ }^{9}$, flank angle, the top radius of curvature, and the straight part at the bottom of the thread ${ }^{1}$. Different modifications in thread patterns such as microthreads near the neck of the implant, macrothreads on the mid-body, and variety of altered pitch threads have been employed to accentuate the effect of threads and induce a desired biomechanical behavior ${ }^{36}$.

\section{Biomechanical factors}

Dental implants are primarily anchored in bone by means of mechanical interlocking ${ }^{1}$; therefore, implant stability is considered to play a fundamental role in successful osseointegration. It has been found an implant failure rate of $32 \%$ for implants with inadequate initial stability ${ }^{36}$. As mentioned above, major contributors to dental implant stability are the design parameters such as length, diameter, geometry and threads have important effects on biomechanical stability, load transfer mechanisms and either success or failure of implants ${ }^{9}$. Other factors that affect the stability are the material properties and the quality and quantity of surrounding bone $\mathrm{e}^{43,44}$.

Masticatory forces acting on dental implants can also result in undesirable stress within the surrounding jawbone, and this can cause bone rejection and eventual failure of the implant ${ }^{8}$. Moreover, bone resorption can be activated by surgical trauma or bacterial infection, as well as by the design parameters used $^{43}$.

\section{Surface characteristics}

When a material is placed in the body, there will be a biological response that will be mediated by the interaction of the implant through its surface. Micro-level features are included to impart osseointegration or direct bone to implant contact at the micro level ${ }^{21}$.

At the points of contact between cells and biomaterials there is an exchange of information leading to activation of specific genes and remodeling. The first step in this response involves the adsorption of specific proteins, lipids, sugar, and ions that can activate cells mechanisms to induce either acceptance or rejection of the implant by determining which and how many cells populate the surface ${ }^{1,45,46}$.

Therefore, a high percentage of bone-implant contact is necessary to create sufficient anchorage of the implant, which is a determinant factor in osseointegration ${ }^{37}$. Two of the most important factors that affect the quality and speed of osseointegration are the physical and chemical nature of the surface of the implant. These properties also have an effect on the maintenance of soft tissue and surrounding bone around the implant ${ }^{2,8}$.

In order to increase the success rate of dental implants, research has focused on the control of surface properties such as morphology, topography, roughness, chemical composition, surface energy, residual stress, the existence of impurities, thickness of $\mathrm{Ti}$ oxide film, and the presence of metallic and nonmetallic compounds on the surface ${ }^{1}$. These properties profoundly influence the osseous and tissue response to the implant by either increasing or decreasing healing times and osseointegration $^{37}$. Research has shown that osteoblastic cells adhere more quickly to rough surfaces than to smooth surfaces ${ }^{1}$. This property can also produce orientation and guide locomotion of specific cell types and has the ability to directly affect cell shape and function ${ }^{37,47}$.

There are two broad types of chemical alterations: 1) addition of inorgainic phases (e.g., hydroxyapatite or calcium phosphates) and 2) addition of organic phases (growth factors $)^{48}$. In both cases, the goal is to impart direct bone to 
implant contact. The addition of inorganic phases such as calcium phosphates imparts osteoconductive properties to the implant ${ }^{49}$. Coating Ti implants with calcium phosphates increases the speed at which bone formation occurs and also serves to span a gap between bone and the implant ${ }^{50,51}$. Ti implants are typically coated with hydroxyapatite using plasmaspraying to form an inorganic film. Though this coating serves to increase osteoinduction, the bond between the film is a limiting factor in the efficacy of inorganic coatings; the micron-sized film can delaminate or loosen and release large particles, causing implant failure ${ }^{18}$. Secondly, the addition of organic molecules or bioactive molecules also influences the surrounding cells $\mathrm{s}^{1,18,45,46,52,53}$. For those reasons most commercial dental implants have a microroughened surface $(0.5-1 \mu \mathrm{m})^{7,54}$ obtained by techniques such as grit-blasting and/or acidetching $^{54}$.

Although many studies have demonstrated the importance of roughness in osseointegration, there is no standard for the roughness of dental implants ${ }^{1}$. However, many animal studies support that bone ingrowth into macro rough surfaces (2-3 $\mu \mathrm{m})$ enhances the interfacial and shear strengths. Surface roughness can also induce orientation and guide locomotion of cells and has the ability to directly affect cell shape and function $^{7}$

To increase the surface roughness, the following methods have been described.

\section{1) Machining}

The surface is manufactured and then, implants are subject to cleaning, decontamination, passivation and sterilization; but there is not subsequent finishing, meaning that the surface is untreated ${ }^{1,2}$.

\section{2) Plasma spraying}

This is one of the most common method in which powders of different substances (e.g., Ti or calcium phosphates) are heated to high temperatures and then are projected onto roughened implant surfaces to form coatings between $30 \mu \mathrm{m}$ to $50 \mu \mathrm{m}$ thick $^{55}$. This technique imparts a rough surface with an average roughness of $7 \mu \mathrm{m}^{18}$ and increases the surface area of the implant up to 6 times the initial surface area, ${ }^{2,7,18,56}$. Although thickness of the coating depends on particle size, speed and time of impact, temperature, and distance from the nozzle tip to the implant surface area ${ }^{37}$, it normally ranges from $10-40 \mu \mathrm{m}$ for $\mathrm{Ti}$ and $50-70 \mu \mathrm{m}$ for $\mathrm{HA}^{18}$, improving the osseointegration process over uncoated implants. However, studies have shown that these coatings may be partially dis- solved/resorbed after long periods in use $\mathrm{e}^{1,56}$. Plasma-sprayed coatings can increase the mechanical fixation of implants in vivo ${ }^{57}$, however Ong et al. ${ }^{58}$ concluded that Ti plasma sprayed and hydroxyapatite plasma sprayed implants were only beneficial in the initial healing period. It should also be noted that the interface between the coating and the implant is limiting factor in the success of plasma-sprayed implants. Delamination or resorption of the coating can cause a loss of mechanical integrity and adverse biological reactions such as periimplantitis $^{48,58}$

\section{3) Machine grit-blasting}

This is one of the most frequently methods of surface alterations, in which the implant surface is roughened by projecting hard particles (alumina or $\mathrm{TiO}_{2}$ ) at high velocities at implants to alter the surface roughness ${ }^{2,18,37}$. Roughness depends on particle size, time of blasting, pressure and distance from the source of particle to the implant surface. The main advantages of this technique is that it improves adhesion, proliferation and differentiation of osteoblasts. On the other hand, one of the major disadvantages is that particles are left on the surface after blasting ${ }^{1,7,56}$. Grit blasted Ti implants to a roughness of $1.5 \mu \mathrm{m}$ have shown to exhibit a greater bone response as determined by removal torque when compared to turned implants, though it is difficult to determine if blasted surfaces are advantageous based off clinical studies ${ }^{59}$.

\section{4) Acid-etching}

This technique consists on increasing the thickness of the oxide layer and the roughness by immersing the metallic implant into an acidic solution ( $\mathrm{HCl}$ or $\mathrm{HF}$ ) which erodes the surface producing micro pits with sizes ranging from 0.5-2 $\mu \mathrm{m}^{2,18}$. The factors that determine the result of the chemical attack are the concentration of the acidic solution, time, and temperature of the process ${ }^{37}$. The major advantage of the acid treatments is that they provide homogeneous roughness, increased active surface area and improve cells adhesion, and therefore rapid osseoinegration ${ }^{1}$. Modifications of the technique have been proved to induce higher adhesion of cells and expression of genes involved in the promotion of osseointegration. Among this modifications, we find the dual-acid etched technique and sandblasted and acid-etched method (sand-blasted, large grit, acid-etched) ${ }^{2,7,56}$. Acid etched implants have been seen to have a higher implant stability quotient compared to machined screws using a polymer to simulate bone ${ }^{60}$. As reviewed by Wennerberg and Albrektsson ${ }^{59}$, etched surfaces with roughness of $0.6 \mu \mathrm{m}$ to $0.9 \mu \mathrm{m}$ have 
significantly higher removal torque values and in most cases, a higher bone in contact area when compared to machine grit blast implants and machine turned controls.

\section{5) Anodization}

It is an electrochemical process where the implant is immersed in an electrolyte while a current is applied, resulting in micropores of variable diameter and an increase of the oxide layer ${ }^{1,2,7,18}$. Main advantages of anodization technique include improved biocompatibility, increased cell attachment and proliferation ${ }^{7}$.

\section{6) Laser treatment}

Although peri-implantitis has been commonly treated with systemic administration of antibiotics, the success has been limited due to resistant strains of bacteria and ineffective antibiotic dosages ${ }^{61}$. Dental lasers have become popular for sterilization and cleaning of implant surfaces ${ }^{62}$. It is believed that the decontamination of the implant is caused by the physical properties of the laser energy and its interaction with tissues, due to reflection, scattering, transmission, absorption and slight temperature elevation ${ }^{61,63}$. Other technique, laser peeing consists on surface bombardment with small spherical particles that causes small indentations or dimples using a laser beam striking a protective layer on the metallic surface ${ }^{64}$.

\section{7) Coating}

Dental implants can be coated with a variety of materials and/or molecules depending on the specific application and requirements. One example includes coating the surface with calcium phosphates to produce bioactive surfaces that enhance bone-to-implant contact ${ }^{2,46}$. It is known that fluoride ions can lead to increased calcification of the bone, and for this reason, dental implants have also been coated with fluoride ions ${ }^{1}$. Moreover, since osteoblasts recognize specific molecules it is possible to coat implant surfaces with immobilized molecules to improve cell attachment, protein deposition and mineralization. These immobilized molecules include amino acid sequences (arginine-glycin-aspartic acid, or RDG), vitronectin, collagen, functional groups, pharmacological substances (biophosphonates) ${ }^{45,46}$, and antimicrobial agents (e.g., tetracycline) ${ }^{7}$.

\section{Medical status of the patient}

In healthy patients, the success rates most dental implants range between $90 \%-95 \%$ at 10 years $^{65}$, and although many design factors play an important role on implant success, clinical studies demonstrate that patient's health conditions and bone quality are important determinants of dental implant survival $^{2,66}$.

In general, systemic risk factors can increase the risk of treatment failure or complications, but very few absolute contraindications to dental implant treatment are defined ${ }^{65,66}$. Conditions that increase the risk of failure include but are not limited to smoking and endocrine disease (tooth and implant loss related to vasoconstriction and tissue hypoxia), osteoporosis (reduction in alveolar bone density and mass due to the altered bone metabolism), microbial and immuneinflammatory factors, cardiovascular disease, myocardial infarction, cerebrovascular accident, severe bleeding issues, and chemotherapy ${ }^{65,66}$. Nonetheless, it has been suggested that the degree of disease-control may be more important that the nature of the systemic disorder itself, and careful evaluation of the patient must be done before starting the treatment with dental implants ${ }^{65,67}$.

\section{Bone quality}

Although dental implants are a very common and well known technique, failures of up to $10 \%$ are still encountered. In general, these failure rates have been associated with poor bone quality and/or quantity ${ }^{36,68}$ which leads to poor anchorage and stability of the implant ${ }^{69}$.

Bone quantity relates to the degree of bone density present. Although bone quality can improve around a functional osseointegrated dental implant due to the positive bone stimulation, the more bone that is present at an implant site, the better the possibility for implant success. On the other hand, bone quality can be described by factors other than bone density such as skeletal size, the architecture and 3-dimensional orientation of the trabeculea, matrix properties, mineralization, and structure. Bone quality is categorized into four groups according to the proportion and structure of compact and trabecular bone tissue ${ }^{68,70}$.(Table 1)

Several approaches such as densitometric measurements, dual energy X-ray absorptiometry, computer tomography (CT) and dental cone-beam CT have been used to measure jawbones density ${ }^{68}$. Most literature reviews present some indication of positive correlation between primary stability of dental implants and bone density of receptor site. As the bone density increases, the primary stability of implants also increases, but a complete assessment of the patient has to be done and the decision of treatment is subject to the specialist opinion ${ }^{70}$. 
Table 1. Bone quality categories and possible outcomes after implantation ${ }^{68}$

\begin{tabular}{ll}
\hline \multicolumn{1}{c}{ Type } & Bone quality category \\
\hline $\begin{array}{l}\text { I: Homogeneous cortical bone } \\
\text { II: Thick cortical bone with marrow cavity }\end{array}$ & $\begin{array}{c}\text { Dense bone, which provides great cortical anchorage, but limited vascularity. } \\
\text { The best bone for osseointegration of dental implants. It provides good cortical } \\
\text { anchorage for primary stability, yet has better vascularity than Type I bone. }\end{array}$ \\
$\begin{array}{l}\text { III: Thin cortical bone with dense trabecular bone of good strength } \\
\text { IV: Very thin cortical bone with low density trabecular bone of } \\
\text { poor strength }\end{array}$ & $\begin{array}{l}\text { Highe least success, but better than type IV bone. } \\
\text { in the posterior mailure compared with the other types of bones. Often found }\end{array}$ \\
\hline
\end{tabular}

Laura Gaviria et al: Current trends in dental implants. J Korean Assoc Oral Maxillofac Surg 2014

\section{Surgical technique}

Dental implants have been used as a solution for close to a half century, and although there are many indications for practitioners in terms of procedures, there are multiple different implant systems on the market that require the own judgment of the specialist ${ }^{71}$. There are few guidelines that describe when or where to use the different types of implants available ${ }^{9}$. Therefore, specialists are trained on the safe and successful placement and maintenance of dental implants, associated risks, benefits and alternatives, and the ability to quickly recognize and treat all of the various potential complications ${ }^{72}$.

\section{Current Implant Design Trends}

\section{Finite element analysis}

Failure of implants is a relatively common problem, and there is a need of analysis of the abutments ${ }^{39}$. FEA is becoming a common method in implant dentistry that allows engineers/scientists to study jawbone and implant properties, and bone-implant interface as well as to understand how to improve implant design in order to function within physiological acceptable limits. FEA consists on a computerized threedimensional model that has been extensively used to predict the characteristics of stress distribution in bone surrounding implants, which are influenced by both the implant dimensions and the biomechanical bond formed between the bone and the implant ${ }^{37,38,43}$.

\section{Computer-aided design and computer-aided manufacturing technology}

Implants and abutment fabrication has and continues to undergo significant metamorphosis, and since nowadays, complicated shape implants and abutments are used, CAD/
CAM techniques are being implemented. The advantages of the technique are accuracy and less time required for manufacturing the parts ${ }^{39,73}$.

\section{Micro casting}

Using a metal melt which is cast into a micro structured mold, the micro casting technique enables the manufacture of small structures and complex geometrical details in the micrometer range. The advantages are relatively low cost and scalability from single items to large numbers of identical items ${ }^{39}$.

\section{Electron microscopy}

Sometimes, it is important to study the effect of the phase composition of the surface oxide layer. However, since the oxide layer is very thin and many of the techniques are used for flat surfaces, analyzing complex geometry implants with increased surface roughness becomes a difficult task. Microscopy techniques such as high resolution transmission electron microscopy allows accurate measurements of the lattice parameters as well as analysis of the microstructure and grain sizes of the surface layer. In addition, electron diffraction can be used for phase identification on nanoscale features. Electron backscattering diffraction detection using scanning electron microscopy allows electron diffraction analysis of surface films without extensive sample preparation ${ }^{46}$.

\section{Nanotechnology-based implants}

Nanotechnology approaches require novel ways of manipulating matter in the atomic scale. Currently, extensive research on techniques to produce nanotechnology-based implants are being investigated ${ }^{74}$. Nanotechnology-based trends for dental implants consist on surface roughness modification at the nanoscale level to promote protein adsorption and cell 
adhesion, biomimetic calcium phosphate coatings, and the incorporation of growth factors for accelerating the bone healing process ${ }^{18}$.

Most attempts to get nanoroughness have used processing methods like lithography and surface laser-pitting, but only a few studies have reported modifications to the roughness as well as the chemistry at the nanometer scale in a reproducible manner. Other technique is the deposition of nanoparticles like biomimetic calcium phosphate, alumina, titania, zirconia $^{18,75}$, and other materials to coat Ti surfaces ${ }^{56,74}$. The surface of Ti dental implants can also be coated with bone-stimulating agents such as growth factors (transforming growth factor- $\beta$, bone morphogenetic proteins [BMPs], platelet-derived growth factors and insulin-like growth factor [IGF]-1 and 2) and antiresorptive drugs (biophosphonates) in order to enhance the bone healing process locally ${ }^{18,76}$. In one study, a Ti machine smooth implant was compared to a Type-1 collagen coated Ti implant and a Type-1 collagen-BMP-2 coated implant $^{77}$. The results of this animal study showed greatest periimplant bone formation within the grooves of the endosseous screw for the collagen-BMP implant when compared to the collagen-coated implant. In this example, both collagen and BMP-2 serve as bioactive molecules. In addition to adding biomolecules which promote bone growth, molecules such as biophosphonates which prevent bone resorption may also be added.

In terms of surface modification at the grain boundaries level, one approach involves the physical method of compaction of nanoparticles of $\mathrm{TiO}_{2}$ versus the compaction of micron-level particles to yield surfaces with nanoscale grain boundaries ${ }^{18,74}$. Other interesting approach is the process of molecular self-assembled monolayers which are formed by the spontaneous positioning of molecules on the surface, exposing only the end-chain group(s) at the interface which can have osteoinductive or cell adhesive molecules such as RGD domains $^{74}$.

\section{Functionally graded materials}

As described by Mehrali et al. ${ }^{78}$ in 2013, the suitable design of porous bone with a porosity gradient from a dense, stiff external structure (the cortical bone) to a porous internal one (the cancellous bone), and with an adequate degree of interconnectivity exhibits that functional gradation is applied by biological adaptation. Therefore, functionally graded materials (FGMs) are gaining attention in dental implant applications. FGM is a heterogeneous composite material including a number of constituents that exhibit a compositional gradient from one surface of the material to the other subsequently, resulting in a material with continuously varying properties in the thickness direction. This design creates an optimized mechanical behavior and improves biocompatibility and osseointegration $^{78}$.

\section{Conclusion}

With a long history of dental implantology and ever since modern dental implants were introduced more than 40 years ago, the development of the ideal implant has been a major research subject in the field, thereby changing the practice of implant dentistry. Through research, dental implant technology has been constantly improving in the recent years, providing patients with unparalleled levels of effectiveness, convenience, and affordability.

Several design parameters have been evaluated and many designs have also been tested. Although design and implantation requirements such as biomaterials, biomechanical behavior, geometry of the implant, medical condition of the patient, and bone quality have been defined, it is still necessary to further evaluate and understand the correlation of those variables in the long term success of the dental implant. As such, more research on better dental implant materials, design parameters, surface treatment technologies and analysis techniques is still required to improve the outcomes.

\section{Conflict of Interest}

No potential conflict of interest relevant to this article was reported.

\section{References}

1. Elias CN. Factors affecting the success of dental implants [Internet]. Rijeka: InTech [cited 2014 Apr 22]. Available from: http://www. intechopen.com/books/implant-dentistry-a-rapidly-evolving-practice/factors-affecting-the-success-of-dental-implants.

2. Searson LJ. History and development of dental implants. In: Narim L, Wilson HF, eds. Implantology in general dental practice. London, Chicago: Quintessence Publishing Co; 2005:19-41.

3. DiGiallorenzo D. History of dental implants [Internet]. Collegeville (PA): Lanap \& Implant Center of Pennsylvania [cited 2014 Apr 21]. Available from: http://www.perioimplants.us/history-ofdental-implants.html.

4. Sullivan RM. Implant dentistry and the concept of osseointegration: a historical perspective. J Calif Dent Assoc 2001;29:737-45.

5. Mijiritsky E, Mazor Z, Lorean A, Levin L. Implant diameter and length influence on survival: interim results during the first 2 years of function of implants by a single manufacturer. Implant Dent $2013 ; 22: 394-8$ 
6. Oral and maxillofacial surgeons: the experts in face, mouth and jaw surgery [Internet]. Rosemont (IL): American Association of Oral and Maxillofacial Surgeons [cited 2014 Apr 21]. Available from: http://www.aaoms.org/conditions-and-treatments/dental-implants.

7. Gupta A, Dhanraj M, Sivagami G. Status of surface treatment in endosseous implant: a literary overview. Indian J Dent Res 2010;21:433-8.

8. Seth S, Kalra P. Effect of dental implant parameters on stress distribution at bone-implant interface. Inter J Sci Res 2013;2:121-4.

9. Lee JH, Frias V, Lee KW, Wright RF. Effect of implant size and shape on implant success rates: a literature review. J Prosthet Dent 2005;94:377-81.

10. Dental implants: histroy of dental implants [Internet]. [place unknown]: Manoimplantai [cited 2014 Apr 22]. Available from: http://www.manoimplantai.lt/dantu-implantai/dantu-implantuistorija/?lang=en.

11. Dental implant history [Internet]. Albufeira: Cris Piessens Clinic [cited 2014 Apr 22]. Available from: http://www.crispiessensclinic. com/implant_history.html.

12. History [Internet]. Chicago (IL): American Academy of Implant Dentistry [cited 2014 Apr 22]. Available from: http://www.aaid. com/about/History.html.

13. Find out who was responsible for starting dental implant history [Internet]. [place unknown]: Dental-Health-Advice [cited 2014 Apr 22]. Available from: http://www.dental-health-advice.com/dentalimplant-history.html.

14. Kawahara H, Kawahara D. The history and concept of implant [Internet]. Tokyo: AQB Implant System [cited 2014 Apr 22]. Available from: http://www.aqb.jp/english/file/TheBasicsPart1.pdf.

15. Nobel Biocare has a 40-year heritage of scientific research and innovation [Internet]. Zürich-Flughafen: Nobel Biocare [cited 2014 Apr 22]. Available from: http://corporate.nobelbiocare.com/en/ourcompany/history-and-innovations/.

16. Rethman MP. Introduction \& historical perspectives on dental implants. Chicago: Hu-Friedy; 2010:1-4.

17. Han HS. Design of new root-form endosseous dental implant and evaluation of fatigue strength using finite element analysis [master's thesis]. Iowa: The University of Iowa; 2009.

18. Le Guéhennec L, Soueidan A, Layrolle P, Amouriq Y. Surface treatments of titanium dental implants for rapid osseointegration. Dent Mater 2007;23:844-54.

19. Javed F, Ahmed HB, Crespi R, Romanos GE. Role of primary stability for successful osseointegration of dental implants: factors of influence and evaluation. Interv Med Appl Sci 2013;5:162-7.

20. Meltzer AM. Primary stability and initial bone-to-implant contact: the effects on immediate placement and restoration of dental implants. J Implant Reconstruct Dent 2009;1:35-41.

21. Stanford CM. Surface modifications of dental implants. Aust Dent J 2008;53(Suppl 1):S26-33.

22. Steigenga JT, al-Shammari KF, Nociti FH, Misch CE, Wang HL. Dental implant design and its relationship to long-term implant success. Implant Dent 2003;12:306-17.

23. Chamay A, Tschantz P. Mechanical influences in bone remodeling. Experimental research on Wolff's law. J Biomech 1972;5:173-80.

24. Huiskes R, Weinans H, Grootenboer HJ, Dalstra M, Fudala B, Slooff TJ. Adaptive bone-remodeling theory applied to prostheticdesign analysis. J Biomech 1987;20:1135-50.

25. Kan JY, Rungcharassaeng K, Kim J, Lozada JL, Goodacre CJ. Factors affecting the survival of implants placed in grafted maxillary sinuses: a clinical report. J Prosthet Dent 2002;87:485-9.

26. Geng JP, Xu DW, Tan KB, Liu GR. Finite element analysis of an osseointegrated stepped screw dental implant. J Oral Implantol 2004;30:223-33.

27. Chun HJ, Cheong SY, Han JH, Heo SJ, Chung JP, Rhyu IC, et al. Evaluation of design parameters of osseointegrated dental implants using finite element analysis. J Oral Rehabil 2002;29:565-74.

28. Motoyoshi M, Yano S, Tsuruoka T, Shimizu N. Biomechanical ef- fect of abutment on stability of orthodontic mini-implant. A finite element analysis. Clin Oral Implants Res 2005;16:480-5.

29. Geng JP, Ma QS, Xu W, Tan KB, Liu GR. Finite element analysis of four thread-form configurations in a stepped screw implant. J Oral Rehabil 2004;31:233-9.

30. Eraslan O, Inan O. The effect of thread design on stress distribution in a solid screw implant: a 3D finite element analysis. Clin Oral Investig 2010;14:411-6.

31. Steigenga J, Al-Shammari K, Misch C, Nociti FH Jr, Wang HL. Effects of implant thread geometry on percentage of osseointegration and resistance to reverse torque in the tibia of rabbits. J Periodontol 2004;75:1233-41.

32. Chong L, Khocht A, Suzuki JB, Gaughan J. Effect of implant design on initial stability of tapered implants. J Oral Implantol 2009;35:130-5.

33. Kim JW, Baek SH, Kim TW, Chang YI. Comparison of stability between cylindrical and conical type mini-implants. Mechanical and histological properties. Angle Orthod 2008;78:692-8.

34. Binon PP. Implants and components: entering the new millennium. Int J Oral Maxillofac Implants 2000;15:76-94.

35. Finger IM, Castellon P, Block M, Elian N. The evolution of external and internal implant/abutment connections. Pract Proced Aesthet Dent 2003;15:625-32, quiz 634.

36. Vidyasagar L, Apse P. Dental implant design and biological effects on bone-implant interface. Stomatologija 2004;6:51-4.

37. Triplett RG, Frohberg U, Sykaras N, Woody RD. Implant materials, design, and surface topographies: their influence on osseointegration of dental implants. J Long Term Eff Med Implants 2003; 13:485-501.

38. Guan H, van Staden R, Loo YC, Johnson N, Ivanovski S, Meredith $\mathrm{N}$. Influence of bone and dental implant parameters on stress distribution in the mandible: a finite element study. Int J Oral Maxillofac Implants 2009;24:866-76.

39. Mandhane SS, More AP. A review: evaluation of design parameters of dental implant abutment. Inter J Emerging Sci Eng 2014;2:64-7.

40. Ivanoff CJ, Sennerby L, Johansson C, Rangert B, Lekholm U. Influence of implant diameters on the integration of screw implants. An experimental study in rabbits. Int J Oral Maxillofac Surg 1997;26:141-8.

41. Shemtov-Yona K, Rittel D, Levin L, Machtei EE. Effect of dental implant diameter on fatigue performance. Part I: mechanical behavior. Clin Implant Dent Relat Res 2012. doi: 10.1111/j.17088208.2012.00477.x. [Epub ahead of print]

42. Himmlová L, Dostálová T, Kácovský A, Konvicková S. Influence of implant length and diameter on stress distribution: a finite element analysis. J Prosthet Dent 2004;91:20-5.

43. Baggi L, Cappelloni I, Di Girolamo M, Maceri F, Vairo G. The influence of implant diameter and length on stress distribution of osseointegrated implants related to crestal bone geometry: a threedimensional finite element analysis. J Prosthet Dent 2008;100:42231.

44. Lan TH, Du JK, Pan CY, Lee HE, Chung WH. Biomechanical analysis of alveolar bone stress around implants with different thread designs and pitches in the mandibular molar area. Clin Oral Investig 2012;16:363-9.

45. Kumar K, Ramesh Bhat TR, Harish PV, Sameer VK, Gangaiah M. Nanobiotechnology approaches to design better dental implant materials. Trends Biomater Artif Organs 2011;25:30-3.

46. Palmquist A, Omar OM, Esposito M, Lausmaa J, Thomsen P. Titanium oral implants: surface characteristics, interface biology and clinical outcome. J R Soc Interface 2010;7(Suppl 5):S515-27.

47. Bonfante EA, Marin C, Granato R, Suzuki M, Hjerppe J, Witek L, et al. Histologic and biomechanical evaluation of alumina-blasted/ acid-etched and resorbable blasting media surfaces. J Oral Implantol 2012;38:549-57.

48. Dohan Ehrenfest DM, Coelho PG, Kang BS, Sul YT, Albrektsson T. Classification of osseointegrated implant surfaces: materials, 
chemistry and topography. Trends Biotechnol 2010;28:198-206.

49. Yuan H, Yang Z, Li Y, Zhang X, De Bruijn JD, De Groot K. Osteoinduction by calcium phosphate biomaterials. J Mater Sci Mater Med 1998;9:723-6.

50. Søballe K. Hydroxyapatite ceramic coating for bone implant fixation. Mechanical and histological studies in dogs. Acta Orthop Scand Suppl 1993;255:1-58.

51. Barrère F, van der Valk CM, Meijer G, Dalmeijer RA, de Groot K, Layrolle P. Osteointegration of biomimetic apatite coating applied onto dense and porous metal implants in femurs of goats. J Biomed Mater Res B Appl Biomater 2003;67:655-65.

52. Ota-Tsuzuki C, Datte CE, Nomura KA, Gouvea Cardoso LA, Shibli JA. Influence of titanium surface treatments on formation of the blood clot extension. J Oral Implantol 2011;37:641-7.

53. Ahn SJ, Leesungbok R, Lee SW. Histomorphometric analysis and removal torque of small diameter implants with alternative surface treatments and different designs. J Oral Implantol 2010;36:263-72.

54. Gil FJ, Manzanares N, Badet A, Aparicio C, Ginebra MP. Biomimetic treatment on dental implants for short-term bone regeneration. Clin Oral Investig 2014;18:59-66.

55. de Jonge LT, Leeuwenburgh SC, Wolke JG, Jansen JA. Organicinorganic surface modifications for titanium implant surfaces. Pharm Res 2008;25:2357-69.

56. Coelho PG, Granjeiro JM, Romanos GE, Suzuki M, Silva NR, Cardaropoli G, et al. Basic research methods and current trends of dental implant surfaces. J Biomed Mater Res B Appl Biomater 2009;88:579-96.

57. Daugaard H, Elmengaard B, Bechtold JE, Jensen T, Soballe K. The effect on bone growth enhancement of implant coatings with hydroxyapatite and collagen deposited electrochemically and by plasma spray. J Biomed Mater Res A 2010;92:913-21.

58. Ong JL, Carnes DL, Bessho K. Evaluation of titanium plasmasprayed and plasma-sprayed hydroxyapatite implants in vivo. Biomaterials 2004;25:4601-6.

59. Wennerberg A, Albrektsson T. Effects of titanium surface topography on bone integration: a systematic review. Clin Oral Implants Res 2009;20(Suppl 4):172-84.

60. Dos Santos MV, Elias CN, Cavalcanti Lima JH. The effects of superficial roughness and design on the primary stability of dental implants. Clin Implant Dent Relat Res 2011;13:215-23.

61. Romanos G, Ko HH, Froum S, Tarnow D. The use of $\mathrm{CO}(2)$ laser in the treatment of peri-implantitis. Photomed Laser Surg 2009;27:381-6.

62. Park CY, Kim SG, Kim MD, Eom TG, Yoon JH, Ahn SG. Surface properties of endosseous dental implants after NdYAG and
$\mathrm{CO} 2$ laser treatment at various energies. J Oral Maxillofac Surg 2005;63:1522-7.

63. Romanos GE, Gutknecht N, Dieter S, Schwarz F, Crespi R, Sculean A. Laser wavelengths and oral implantology. Lasers Med Sci 2009;24:961-70.

64. Parekh RB, Shetty O, Tabassum R. Surface modifications of endosseous dental implants. Int J Oral Implantol Clin Res 2012;3:11621.

65. Diz P, Scully C, Sanz M. Dental implants in the medically compromised patient. J Dent 2013;41:195-206.

66. Paquette DW, Brodala N, Williams RC. Risk factors for endosseous dental implant failure. Dent Clin North Am 2006;50:361-74.

67. Scully C, Hobkirk J, Dios PD. Dental endosseous implants in the medically compromised patient. J Oral Rehabil 2007;34:590-9.

68. Gulsahi A. Bone quality assessment for dental implants. Rijeka: InTech; 2011:437-52.

69. McNutt MD, Chou CH. Current trends in immediate osseous dental implant case selection criteria. J Dent Educ 2003;67:850-9.

70. Marquezan M, Osório A, Sant'Anna E, Souza MM, Maia L. Does bone mineral density influence the primary stability of dental implants? A systematic review. Clin Oral Implants Res 2012;23:76774.

71. Ogden A, British Society for the Study of Prosthetic Dentistry. Guidelines in prosthetic and implant dentistry. London: Quintessence Publishing; 1996.

72. Anson D, Johnson B, Korb P, Leopardi A, Lytle L, Malmquist J, et al. Recommended training guidelines for basic implant placement. Santa Monica (CA): Institute for Dental Implant Awareness; 2009.

73. Sonick M. Implant dentistry: evolution and current trends--the times they are A-Changin. Inside Dent 2006;2:86-90.

74. Mendonça G, Mendonça DB, Aragão FJ, Cooper LF. Advancing dental implant surface technology--from micron- to nanotopography. Biomaterials 2008;29:3822-35.

75. Özkurt Z, Kazazoğlu E. Zirconia dental implants: a literature review. J Oral Implantol 2011;37:367-76.

76. Tomsia AP, Launey ME, Lee JS, Mankani MH, Wegst UGK, Saiz E. Nanotechnology approaches for better dental implants. Int J Oral Maxillofac Implants 2011;26:25-49.

77. Schliephake H, Aref A, Scharnweber D, Bierbaum S, Roessler $\mathrm{S}$, Sewing A. Effect of immobilized bone morphogenic protein 2 coating of titanium implants on peri-implant bone formation. Clin Oral Implants Res 2005;16:563-9.

78. Mehrali M, Shirazi FS, Mehrali M, Metselaar HS, Kadri NA, Osman NA. Dental implants from functionally graded materials. J Biomed Mater Res A 2013;101:3046-57. 